Jpn. J. Health Phys., 43 (4), 359 - 365 (2008)

\title{
Review
}

\section{Current Situation of Radiation Protection in Vietnam}

\author{
Toan Ngoc Tran $* 1, * 2$
}

(Received on December 3, 2007)

(Accepted on August 6, 2008)

\begin{abstract}
Vietnam was one of the earliest countries, who applied ionizing radiation in medicine, since 1923, Dr. Marie Curie had supplied radium sources to Hanoi cancer hospital for radiotherapy. However, we did not give sufficient attention to radiation protection involving, e.g. technology, legislation, until 1980s. Recently with the strong support from International Atomic Energy Agency (IAEA) and Vietnam government nuclear technology has been strongly and widely developed in different branches and radiation protection situation in Vietnam has been improved step by step. Strategy for Peaceful Utilization of Atomic Energy up to 2020 approved by the prime minister on January $3^{\text {th }}, 2006$ confirms that nuclear power plant will be put in operation by 2020 . To ensure the implementation of the strategy, the first priority should be given to radiation protection and nuclear safety. This paper presents shortly some activities of radiation safety in Vietnam. The requirements for developing this field in Vietnam are also discussed.
\end{abstract}

KEY WORDS: radiation protection, radioisotope, radioactivity, atomic energy, radiation monitoring, peaceful utilization, exposure control, and nuclear power.

\section{INTRODUCTION}

Although the application of the atomic energy in Vietnam has been established and developed for more than 30 years, radiation protection was not paid attention to on both aspects, legislation and technique. The first technical activities on radiation protection were only initiated in 1980. The national management on radiation protection and nuclear safety started from 1994 when Vietnam Radiation Protection and Nuclear Safety Authority (VRPA) was established. In 1997 the Ordinance on Radiation Safety and Control (ORSC) went into effect. Recently with a strong support from International Atomic Energy Agency (IAEA) and Vietnam government, nuclear technology has been strongly and widely developed in different branches and radiation protection situation in Vietnam has been improved step by step. Strategy for Peaceful Utilization of Atomic Energy up to 2020 approved by the Prime Minister on January 3, 2006 confirms that nuclear power plant will be put in operation by 2020.1) To ensure that this application of atomic energy will be effective and absolutely safe, the first priority should be given to radiation protection and nuclear safety. This paper presents briefly some activities of radiation safety in Vietnam.

*1 Institute of Nuclear Science and Technology, Vietnam Atomic Energy Commission, 59 Ly Thuong Kiet, Hanoi, Vietnam.

*2 The University of Tokyo, 2-11-16, Yayoi, Bunkyo-ku, Tokyo 1130032, Japan.

\section{CURRENT SITUATION OF RADIATION PROTECTION IN VIETNAM}

2.1 Developing \& improving the regulatory infrastructure

\subsubsection{Legislative Framework}

The general Vietnam legislative framework on radiation protection \& control is shown in Fig. 1. At present, an Atomic Energy Law is being drafted and expected to submit to the National Assembly in 2007 so the ORSC is the legal document of highest effect for regulating radiation safety. ORSC was passed on June 25 th 1996 by the Standing Committee of the National Assembly of the Socialist Republic of Vietnam and went into effect on January $1^{\text {st }}, 1997 .^{2)}$ There are 8 chapters with 38 articles in this ORSC. Decree 50/1998/ND-CP, which explains the detailed directions for implementing the ORSC, was enacted on July 16th, 1998 by the Prime Minister of the Socialist Republics of Vietnam and went into effect on August $1^{\text {st }}, 1998 .^{3)}$ There are 7 chapters with 49 articles in this decree. Decree 51/CP/2006, which regulates the punishment for violation of ORSC and Decree 50/CP/1998 was enacted on May $11^{\text {th }}, 2006$ by Prime Minister.

The codes of practices for radiation safety in radiotherapy, nuclear medicine, diagnostic radiology, industrial radiography and industrial irradiation facilities are available for approval.

Vietnam also has participated in some of international treaties related to atomic energy such as the Treaty on the Non-Proliferation of Nuclear Weapons (1982), the Nuclear Safeguards Agreement (1989), the South East Asian NuclearWeapon Free Zone Treaty (1996) and the Comprehensive Nuclear Test Ban Treaty (1996). 


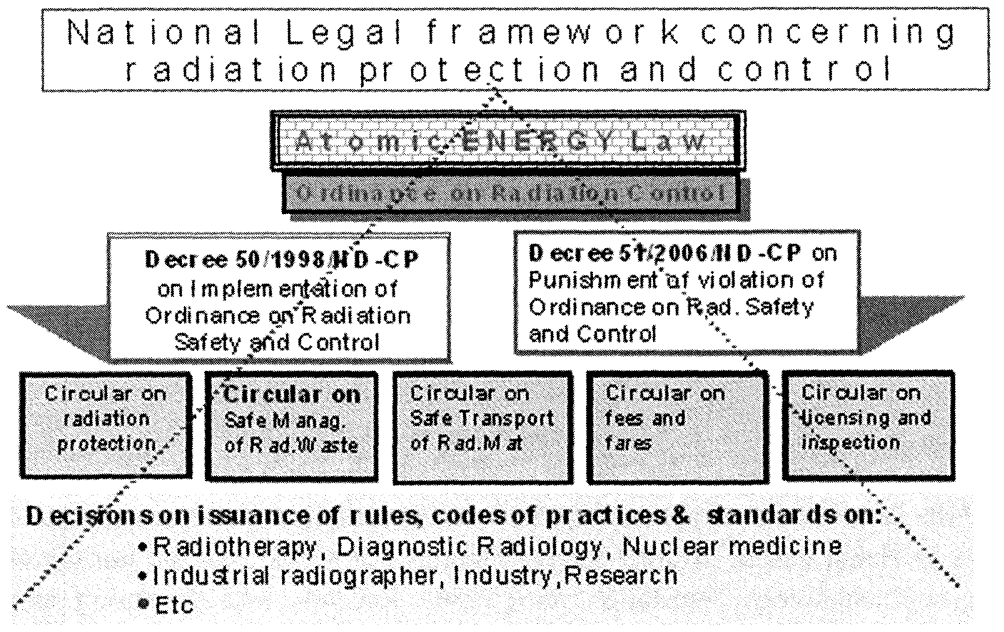

Fig. 1 Vietnam Legislative framework concerning radiation protection and control.

\subsubsection{Regulatory body}

MOSTE (Ministry of Science, Technology and Environment) (now it is renamed Ministry of Science and Technology (MOST)) has been assigned as the regulatory body under the Article 29 of ORSC and the Article 34 of Decree $50 / 1998 /$ ND-CP. To assist the minister of MOST in state management of radiation protection and nuclear safety, Vietnam Radiation Protection and Nuclear Safety Authority (VRPA) was established by the Decision No. 389/TTg of the Prime Minister of July 30 th 1994 and Decision No 159/QDTCCB of Minister of MOST of March $4^{\text {th }}, 1995$. At that time, diagram of state management in radiation and nuclear safety $\&$ control (old version) was demonstrated as Fig. 2.

To ensure that the state management on atomic energy promotion is more independent from the state management of radiation protection and nuclear safety, VRPA was upgraded into Vietnam Agency for Radiation and Nuclear Safety \& Control (VARANSAC) by the Governmental Decree 54/2003/ ND-CP and Decision $1073 / \mathrm{QD}-\mathrm{BKHCN}$ dated June $20^{\text {th }}$, 2003 of MOST. At present time, diagram of state management in radiation and nuclear safety \& control (new version) was

Diagram of State Management in Radiation and Nuclear Safety \& Control (old version)

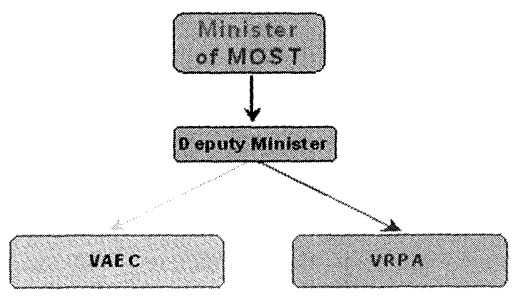

Fig. 2 Diagram of State Management in Radiation and Nuclear Safety \& Control. (old version) demonstrated as Fig. 3. Where MOST is a regulatory body responsible to government for the execution of unified state management on radiation safety and control throughout the country, responsible for organizing and directing all radiation safety and control activities within its function and duties. VARANSAC assists MOST in performing the function of state management of radiation protection and nuclear safety according to the function, and responsibilities of the new agency were defined in the Articles 34 of the Decree 50/1998/ ND-CP and Decree 54/2003/ND-CP. According to the article 42 of the Decree 50/CP the Departments of Science and Technology (DOST) of 64 provinces/cities under direction of MOST are also involved in the provincial management of radiation protection such as issuing a license for diagnostic radiology departments and reporting regularly to MOST via VARANSAC. Under direction of the MOST, besides the state responsibility of atomic energy promotion, Vietnam Atomic Energy Commission (VAEC) is mobilized to assist the VARANSAC on the following aspects: performing the technical radiation protection services such as calibration, personal dose monitoring; reviewing SAR; doing safety assessments, analysis.

\subsection{Establishing the occupational exposure control \\ 2.2.1 Personal dose monitoring}

Since 1986 Laboratory of Radiation Dosimetry, Center of Radiation Protection has been developing and using the thermoluminescence dosemeters (TLD) made from Vietnam natural $\mathrm{CaF}_{2}$ for personal and environmental radiation monitoring. ${ }^{4)}$ The lead compensating filters have been used to improve the energy dependence of $\mathrm{CaF}_{2}$. TLD badges with two TL dosemeters with and without filter are used to measure both effective energy and exposure simultaneously.

Nowadays, in Vietnam there are two service centers for monitoring personal radiation dose by TLD; one located in Dalat Nuclear Research Institute (DNRI) servicing the southern region and the other one belonging to Hanoi Institute for Nuclear Science and Technology (INST) servicing the north- 
Diagram of State Management in Radiation and Nuclear Safety \& Control (new version)

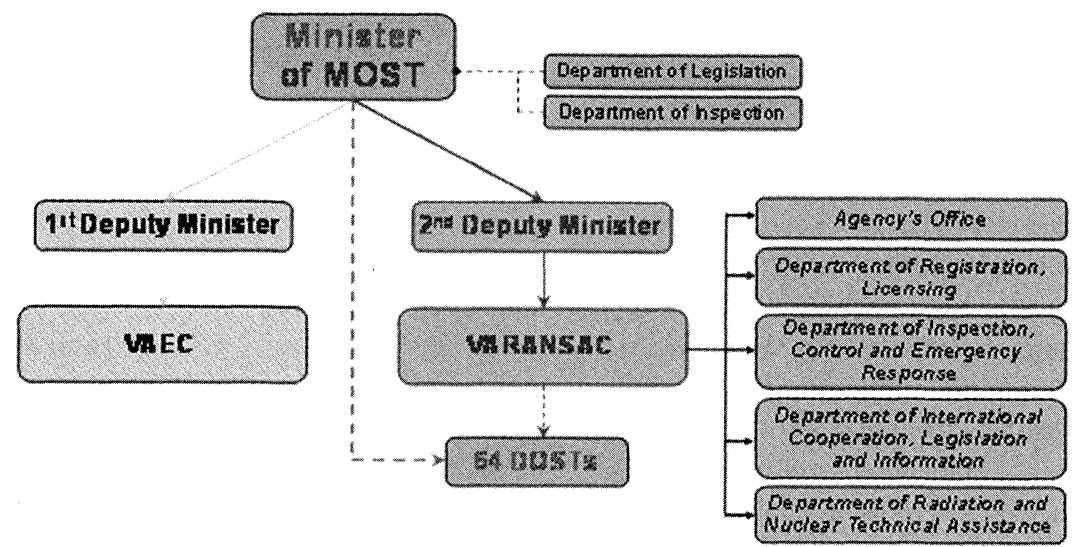

Fig. 3 Diagram of State Management in Radiation and Nuclear Safety \& Control. (new version)

ern region. Both have been equipped with the universal TLD reader systems: Harshaw 4,000, Harshaw 4,500, Toledo 654 and TL detectors: Harshaw $\mathrm{LiF}, \mathrm{CaSO}_{4}$ made in Australia and $\mathrm{CaF}_{2}, \mathrm{CaSO}_{4}$ made in Vietnam. The individual dosemeters have been calibrated by the X-ray radiation specified in ISO4037 standard and the standard source ${ }^{137} \mathrm{Cs}$, OB6. The quality assurance of two centers was carried out via three phases of personal radiation dosimetry intercomparison within AsiaPacific region. Intercomparison results are good (the uncertainty is not exceed $30 \%$ ) for all energy of X-ray field and protection level.5) Since 2002 the national intercomparison program on determination of operational personal dose equivalents quantities has been carried out. This program will be running regularly. The good results of intercomparison have been recorded.

At present, the operational dose equivalents: such as $\mathrm{Hp}$ (10) and $\mathrm{Hp}(0.07)$ of about 4,000 radiation workers have been evaluated monthly or quarterly by personal TLDs of two laboratories of INST (Hanoi) and DNRI (Dalat). The internal individual monitoring has been set up by using the bioassaymethod (urine samples) at DNRI.6) The internal individual monitoring was carried out mainly for radiation workers producing radioisotopes. It is found out that the most critical groups are groups of radiation workers working for None Destructive Testing (NDT) and isotope production. The dose limits are specified in Vietnam Standard TCVN-6866:2001 consistent with IAEA Basic Safety Standard.

\subsubsection{Surveying radiation safety at workplaces}

The surveys of radiation safety and investigation of radiation level have been carried out along the country from North to South, especially at Monazite, Imelnite sand beaches, X-ray rooms, nuclear medicine departments, workplaces with ${ }^{137} \mathrm{Cs}$ and ${ }^{60} \mathrm{Co}$ and neutron sources. $\left.{ }^{7} \sim 14\right)$ The gamma sensitive survey meters suitable for energy from $20 \mathrm{keV}$ to $3 \mathrm{MeV}$ and neutron survey meters were used for this task. Through these surveys, the working radiation environment and measures for protecting workers from radiation hazard were evaluated to justify the construction, and designation of workplace.

2.2.3 Designing and supervising the construction of the radiation installation.

Many new X-ray rooms were designed and built; old X-ray rooms were rebuilt under supervision of physicists of Radiation Protection Centers in order to meet the requirements of radiation safety. Aiming at radiation safety, suitable utilization, economy and good looking, radiation physicists have taken part in designing and supervising 6 radiotherapy departments with cobalt unit, linac and gamma knife unit.

\subsubsection{Studying on the production of shielding materials} for X-ray protection

4 methods of mixing barium mortar with additional materials such as TD-1 and TD-2 were used to produce shielding materials. ${ }^{15}$ ) The determination of lead equivalent of barite with different levels of thickness at several X-ray sources allowed professional evaluation and calculation of necessary protective thickness of barium mortar for walls of X-ray room. The heavy concrete based the $\mathrm{BaSO}_{4}$ ore was studied to use as shielding wall for the radiation facilities. Based on existing equipment and raw materials in the country, a technological process of lead rubber pieces manufacture was suggested. The quality of these products is as good as imported products.

\subsection{Establishing the medical exposure control}

The special radiation practice license will be granted for persons who are involved in radiotherapy. For strengthening radiation safety in medical practices, the Advisory Council on Radiation Protection was established in Ministry of Health $(\mathrm{MOH})$. The functions of this council are to assist the minister of $\mathrm{MOH}$ in relevant maters such as setting up radiation protection programs for specific practices and drafting the guidance.

2.3.1 Carrying out quality control for radiotherapy equipment.

In Vietnam, up to now there are 13 radiotherapy centers 
with 13 radiotherapy cobalt- 60 sources, 2 gamma knife units, 1 Cyber knife, 7 Linacs, several therapeutic X-ray machines and afterloading machines. Measurement of radiation output of radiotherapy equipment in air and a water phantom under standard conditions at the treatment distance was performed by staff of National Dosimetry Calibration Laboratory (NDCL). Generally, measurements have been done once a year with standard dosimetry system (FARMER electrometer, ionization chambers NE 2571, NE 2581...) traceable to Secondary Standard Dosimetry Laboratory (SSDL) of IAEA. After setting up, commissioning, repairing radiotherapy units and changing the new source, MOH asked NDCL doing acceptance tests for radiotherapy equipment. On-site visit, apart from measurement of radiation output, various parameters of equipment were controlled as follows: ${ }^{16}$ )

- Verification of mechanical parameters including correspondence between the mechanical axis of the collimator and the light beam axis, isocentre position, optical distance meter, symmetry of the collimator jaws, geometrical field size indication.

- Verification of photon beam characteristics including correspondence between the light field and the radiation field at reference depth, flatness and symmetry of radiation field...

Sometimes IAEA experts come to radiotherapy departments to measure beam output of equipment by both expert's and local secondary standard dosimetry systems.

The External Audit Group (EAG) was established on the base of staff and facilities of VAEC, Medical Physics group of radiotherapy departments and officers of VARANSAC and MOH. ${ }^{17)}$ Since 2001 EAG has organized the TLD based quality audit in dosimetry for radiotherapy departments annually.

\subsubsection{Carrying out quality control for diagnostic X-ray machine}

In Vietnam, up to now there are about 2000 diagnostic Xray machines being used in various types (conventional, dental, computed tomographic, angiographic, fluoroscopic,). Among them, there are many old X-ray machines used for more than 10 years, even 20 years. So quality control for Xray machines is a very necessary and important task of medical physicists to reduce dose to patients in diagnostic radiology without any loss of diagnostic information and to maintain the high cost X-ray machines. However in the past due to lack of qualified physicists and equipment all X-ray machines used in Vietnam were not tested. Now with the help of the good quality control tool kits provided by IAEA-TC projects VIE6/019, RAS/9/021 and government fund (such as: multifunction meter RMI-240, PTW-330, Rad-check TM-plus model 06-252, focal spot test tool, CT phantom, Leed test objects ...), many X-ray machines have been controlled. Since 1999, based on the technical document compiled by VAEC staff, Vietnam Directorate for Standards and Quality has issued the protocols named DLVN41 "Conventional diagnostic X-ray equipment-Methods and means of verification", DLVN42 "Computed tomography X-ray equipment-Methods and means of verification" and DLVN65 "Imaging intensifying X-ray equipment-Methods and means of verification". About hundreds of X-ray machines have been tested every year; accep- tance test of new equipment have been paid attention to especially. Recently, the new X-ray beam qualities for diagnostic radiology have been established in NDCL following IAEA code of practice. ${ }^{18)}$

\subsection{Establishing the Public Exposure Control}

To protect the public from radiation hazard, we have to manage the business related to the radioactive materials strictly and set up the Environmental Monitoring Program. VARANSAC are preparing the circular on detailed direction on implementation of Decree 11/1999/ND-CP on business and trade of radioactive consumer products, radioactive materials and radiation devices.

In 1981 two first Environmental Radiation Monitoring Laboratories belonging to VAEC were established in Hanoi and Dalat. Their objectives are:

(1) To monitor the natural radioactive isotopes and artificial radioactive isotopes in environment such as ${ }^{137} \mathrm{Cs},{ }^{90} \mathrm{Sr}$, in Hanoi and around the research reactor in Dalat.

(2) To collect database on radioactive environment to develop a model predicting the public exposure dose for Vietnamese people.

(3) To use the isotopes in the environment as the indicators to study on environmental problems such as erosion, sedimentation and dispersion of air pollution.

(4) To investigate the transfer of radionuclides in the environment.

In order to obtain the above-mentioned objectives, these laboratories were equipped with low background gamma spectrometers with high purity semiconductor detectors (HpGe), NaI, Alpha spectrometer (4 SSB detectors Canberra Alpha Analyst), low background gross alpha and beta counters, $\mathrm{Si}(\mathrm{Li}) \mathrm{SEA}-2110 \mathrm{X}$-ray spectrometer, liquid scintillation counting system, VARIAN 3,800 gas chromatography system, DIONEX 600 ion chromatography system, GENT SFU air samplers and other instruments for collecting, processing environmental samples.

\subsubsection{Routine monitoring}

The environmental monitoring laboratories of INST located in Hanoi, of DNRI located in Dalat and Hochiminh city, of Center for Environmental Processing Engineering, (CEPE), located in Hanoi and Danang are the main establishments involved in environmental radioactive monitoring activities. Since 1998 these laboratories have been approved as the national monitoring stations for radioactive environment by minister of MOSTE and the monitoring network is shown as Fig. 4. Main nuclides in airborne dust and soil, water, plant samples have been monitored and analyzed are:

+ natural: $\quad{ }^{238} \mathrm{U},{ }^{232} \mathrm{Th},{ }^{226} \mathrm{Ra},{ }^{40} \mathrm{~K},{ }^{210} \mathrm{~Pb},{ }^{7} \mathrm{Be}$

+ Anthropogenic: ${ }^{90} \mathrm{Sr},{ }^{137} \mathrm{Cs},{ }^{238} \mathrm{Pu},{ }^{239+240} \mathrm{Pu}$

Table 1 summaries the routine monitoring program of the stations. The program of environmental radioactivity monitoring around Dalat nuclear research reactor established in 1983 (prior to put the research reactor in operation) confirms that during past 24 years, operation of research reactor was absolutely safe and did not release any significant radioactive materials into the surrounding environment of DNRI. During this time the abnormal level of fallout in air was registered 


\section{Organization Chart}

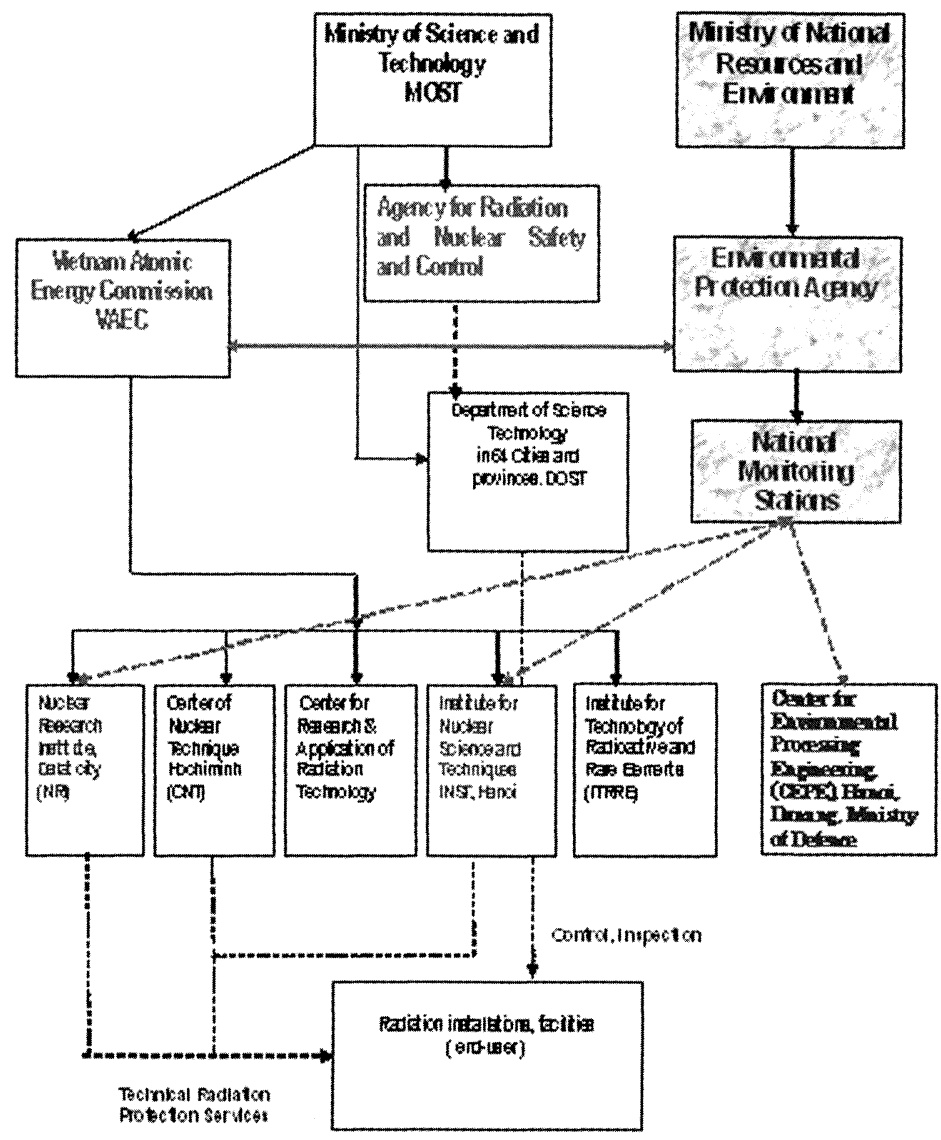

Fig. 4 Current monitoring network for radioactive environment in Vietnam.

Table 1. The routine monitoring program of the stations

\begin{tabular}{|c|c|c|}
\hline Sample & Monitoring items & Period \\
\hline Air sample fallout & $\begin{array}{c}\text { All radionuclides } \\
\text { Gross alpha, beta }\end{array}$ & $\begin{array}{c}\text { Monthly } \\
\text { Quarterly }\end{array}$ \\
\hline Soil & All radionuclides & 2 times in a year \\
\hline Water & $\begin{array}{l}\text { All radionuclides } \\
\text { Gross alpha, beta }\end{array}$ & Quarterly \\
\hline Plant & All radionuclides & Quarterly \\
\hline
\end{tabular}

and evaluated 2 times in Vietnam: ${ }^{19}$

- In May, June/1986 the artificial nuclides as ${ }^{103} \mathrm{Ru},{ }^{131} \mathrm{I}$, ${ }^{144} \mathrm{Ce},{ }^{134} \mathrm{Cs}$ and ${ }^{137} \mathrm{Cs}$ in air were registered in Hanoi, Dalat and Hochiminh city; ${ }^{137} \mathrm{Cs}$ level is $10-100$ time higher than normal background but lower than that of China, Japan about 3 orders; ${ }^{137} \mathrm{Cs} /{ }^{134} \mathrm{Cs}=2.0 \pm 0.2$ in fallout and $2.2 \pm 0.5$ in aerosol already confirmed that origin of this abnormal situation is from Chernobyl accident. The ${ }^{137} \mathrm{Cs}$ peaks occurred in 5 subsequent dry seasons after 1986 proved that cold air plume (with higher radioactivity) from the northern countries (with higher latitude) came to Vietnam during Northern East wind time.

- On 16-17/June/1991, storm Yunga blew the ash dust from Pinatubo volcano (Philippines) to the southern region of Vietnam. Radioactivity of ash sample from Pinatubo) collected in Nha Trang, Dalat, Hochiminh city is shown in Table 2.

\subsubsection{Some typical researches on environmental radiation} also have been carrying out

- Investigation of the distribution of fallout inventory $\left({ }^{90} \mathrm{Sr}\right.$, ${ }^{137} \mathrm{Cs},{ }^{239},{ }^{240} \mathrm{Pu}$ ) in whole Vietnam terrestrial environment ${ }^{20}$ )

- Determination of background gamma dose rate due to terrestrial radionuclides by using TLD, in situ gamma spectrom-

Table 2 Radioactivity of ash sample (from Pinatubo)

Collected in Nha Trang, Dalat, Ho Chi Minh city

\begin{tabular}{|c|c|c|}
\hline Order No. & Items & $\begin{array}{c}\text { Specific activity } \\
(\mathrm{Bq} / \text { ash } \mathrm{kg})\end{array}$ \\
\hline 1 & Gross beta & $598 \pm 25$ \\
\hline 2 & ${ }^{40} \mathrm{~K}$ & $560 \pm 80$ \\
\hline 3 & ${ }^{232} \mathrm{Th}$ & $97.7 \pm 0.4$ \\
\hline 4 & ${ }^{238} \mathrm{U}$ & $134.1 \pm 25.6$ \\
\hline
\end{tabular}


eter and converting radioactivity of $\mathrm{U}, \mathrm{Th}, \mathrm{K}$ in soil samples to that ${ }^{21)}$

- Determination of radioactivity of indoor radon by using two nuclear solid state tract detector (NSSTD) techniques, spark counting and electrochemical etching ${ }^{22}$ )

- Determination of the radioactivities of some main kinds of foodstuff in Vietnam ${ }^{23}$ )

- Development of analytical methods and collection of the base data of ${ }^{90} \mathrm{Sr},{ }^{137} \mathrm{Cs},{ }^{238} \mathrm{U},{ }^{232} \mathrm{Th},{ }^{226} \mathrm{Ra},{ }^{239},{ }^{240} \mathrm{Pu},{ }^{210} \mathrm{~Pb}$ and ${ }^{210} \mathrm{Po}$ in marine environment. ${ }^{24)}$

- Determination of the soil to plant transfer factors of radionuclides $^{25}$ )

- Assessment of enhanced natural radiation background by technologies ${ }^{26)}$ (e.g. thermal power plant, utilization of phosphate fertilizer, exploration and exploitation of oil and gas)

- Modeling the level and extend of dispersion of gases released from a nuclear power plant to be built in the territory of Vietnam. ${ }^{27)}$

\subsection{Management of radioactive waste, radiation safety and security for disused sources and radiation mate- rials}

Radioactive wastes from R\&D activities at VAEC and some other institutions have been collected, classified, treated and stored safely in accordance with international standards. In Vietnam Institute for Technology of Radioactive and Rare Elements (ITRRE) is responsible for national project of management of radioactive wastes. Now they are developing the treatment and interim storage facility of radioactive waste in Phung site located about $20 \mathrm{~km}$ from Hanoi. DNRI is responsible mainly for waste management of research reactor. DNRI has the facility for radiation waste classification, liquid and solid radiation waste treatment systems and the interim store for the cemented radioactive waste. It is known that a large proportion of radiation accidents occurs by spent/disused source. Therefore it is really necessary to manage them carefully for minimizing their impact to environment and human health. At present time, the national inventory of spent radioactive sources has been completed. However a large number of spent radiation sources are being kept at the enduser storages. These sources were registered, but the security measures have to be strengthened. Regarding to spent radiation sources, particularly ${ }^{226} \mathrm{Ra}$ radiation sources (more than 520 items) VARANSAC has requested VAEC to submit a proposal to the IAEA for assistance to condition all radium sources.

\subsection{Emergency Response and Preparedness}

According to our regulation, emergency response and preparedness plan is a precondition for any licensed work with ionizing radiation. So, establishment of emergency response and preparedness plans for the radiation facilities such as research reactor and radioisotope production (Dalat), irradiators ( 2 industrial \& 2 research) radiotherapy units (cobalt units and linacs), nuclear medicine, NDT facilities, waste storage facilities needs the special approval from VARANSAC. However up to now we did not have the national system for Emergency Response and Preparedness, and practical exercises for this activity are rare.

\subsection{Manpower development}

In Co-operation with IAEA, via TC-projects VIE/9/004, VIE/6/019, INT/9/143, and RAS/9/021 many training courses on radiation protection, QA \& QC for radiation facilities in hospital were organized under the instruction of IAEA \& local experts. In co-operation with MOH, VARANSAC and DOST, VAEC have organized many training courses in various levels for radiation workers, radiation safety officers. Many physicists and physician have been trained abroad on radiation protection and related topics. Because knowledge and experience on radiation safety of most radiation workers are very limited these trainings play an important role in improving infrastructure of radiation safety in Vietnam.

The advanced joint Training Center for Radiation Protection between Vietnam Atomic Energy Commission (VAEC) and Japan Atomic Energy Research Institute (JAERI) equipped with very modern instruments has been established at INST since 2001. Annually, 2 courses on radiation protection \& radiation measurement are organized at this center for 40 radiation workers in whole Vietnam; duration of every course is 2 weeks.

\section{Conclusion}

Recently, a big progress on radiation protection has been made in Vietnam. However, many problems still exist such as follows:

- The number of professionals on radiation protection is not enough for the task of radiation protection \& control as well as for the national program on nuclear power. And their knowledge and experience on radiation protection and especially nuclear safety remain limited.

- The radiation protection officers in local DOSTs and companies have not been trained well yet and the instruments and equipment as well as budget for radiation safety at these facilities are not adequate.

In order to meet the requirement of the utilization of atomic energy in Vietnam, some activities on radiation protection should be enhanced as:

- Promulgating the necessary regulations and documents on radiation protection $\&$ nuclear safety to conduct the radiation safety task.

- Performing the national action program on radiation protection \& nuclear safety continuously to upgrade the infrastructure of radiation protection \& nuclear safety in Vietnam as soon as possible.

- Improving the human resources for development of the nuclear safety task to meet the demand of the national program on nuclear power plants.

\section{REFERENCES}

1) Strategy for Peaceful Utilization of Atomic Energy up to 2020 by Vietnam Government, January 3, 2006.

2) Ordinance on Radiation Safety and Control by Standing Committee of Vietnam National Assembly, June 25, 1996.

3) Decree 50/1998/ND-CP on the detail directions for implementing of Ordinance on Radiation Safety and Control by 
Vietnam Government July 16, 1998.

4) Dang Thanh Luong, Pham Quang Dien, Tran Ngoc TOAN, "Development of Personal Thermoluminescent Dosimeters on the base of $\mathrm{CaF}_{2}-\mathrm{N}$ ", Progress Report KX/07/1988 to Vietnam Atomic Energy Commission.

5) Hoang Van Nguyen, "Personnel Dosimetry Service carried out by the Nuclear Research Institute in Vietnam", $2^{\text {nd }}$ IAEA/RCA Personal Dosimeter Intercomparison, Expert Meeting Report, 1-5 December, 1997, BARC, Mumbai, India.

6) Nguyen Van Hung, "Some results on internal radiation dosimetry study", The Annual Report for 1998, VAEC, Science and techniques publishing House, Hanoi (2000) pp. $65-66$.

7) Hoang Van Nguyen, Pham Van Dung "Survey on radiation protection status in Quang Ngai province", DNRIReport 2005.

8) Hoang Van Nguyen, Pham Van Dung and Nguyen Dinh LAM "Survey on radiation protection status in Gia Lai province", DNRI-Report 2004.

9) Hoang Van NGuyen, Phan Dinh SinH "Survey on radiation protection status in Ba Ria - Vung Tau province", DNRI-Report 2003.

10) Ngo Quang HuY, Nguyen Van MAI et al "Survey on radiation protection status in Ben Tre province", HCNTReport 2001.

11) Ngo Quang HuY, Nguyen Van MAI et al "Survey on radiation protection status in Long An province", HCNTReport 2001.

12) Ngo Quang HuY, Nguyen Van MAI et al "Survey on radiation protection status in Binh Duong province", HCNTReport 2001.

13) Ngo Quang HuY, Nguyen Van MAI et al "Survey on radiation protection status in Dong Nai province", HCNTReport 2000.

14) Ngo Quang HuY, Nguyen Van MAI et al "Survey on radiation protection status in Ho Chi Minh city", HCNTReport 1999-2000.

15) Vu Manh Hung, Pham Quang Dien, Le Quang HieP, Ha Son, Tran Ngoc TOAN and Luu Van Chuc, "Study on the production of shielding materials for X-ray protection", Proceedings of the First National Conference on Nuclear Physics and Techniques, Hanoi, 14-15 May 1996.

16) Vietnam Directorate for Standards and Quality, "DLVN 40:1999:Cobalt-60 teletherapy equipment-Methods and means of verification".

17) Dang Thanh Luong, Duong Van Vinh, Ha Ngoc Thach, Vu Manh Khol, Tran Ngoc ToAn, Nguyen Huu Quyet, Nguyen Xuan Ku and Bui Van CUONG, "The TLD based QA in Dosimetry for Radiotherapy", Nuclear Science and Technology, No. 2, December, 2003.

18) Tran Ngoc ToAn, Chu Vu Long, "Establishment of the diagnostic radiology calibration at SSDL-Vietnam", Presentation at $7^{\text {th }}$ National Conference on Nuclear
Physics and Techniques, Danang, August 2007.

19) Pham Quang Dien, Radiation protection activities in Vietnam, Proceedings of International Conference on Application of Ionizing Radiation, Hanoi, 1999.

20) P. D. Hien, H. T. Hiep et al, Derivation of ${ }^{137} \mathrm{Cs}$ deposition density from measurement of ${ }^{137} \mathrm{Cs}$ inventories in undisturbed soils, J Environ. Radioact., 62 (3), 295-303 (2002).

21) Vuong Thu BAC, Nguyen Thanh BiNH et al, "Calibration of spectrometer Nal used for in situ environment measurement", Proceedings of the First National Conference on Nuclear Physics and Techniques, Hanoi, 14-15 May 1996.

22) Nguyen Hao Quang, Ngo Tien Phan, Nguyen Quang Long, Tran Tuyet MAI and Truong Quang CHINH, "Establishing the equipment for calibration of Rn concentration in air", Proceedings of the First National Conference on Nuclear Physics and Techniques, Hanoi, 14-15 May 1996.

23) Nguyen Van PHuc, Nguyen Trong Ngo, Nguyen Thanh BINH and Le Ngoc ChUNG, "Separation and determination of the radioactivity of $\mathrm{U}$, Th in foodstuff by alpha spectrometer", Proceedings of the $6^{\text {th }}$ National Conference on Nuclear Physics and Techniques, Dalat, October 2005.

24) Nguyen Trong Ngo, Nguyen Thanh BiNH et al, "Preconcentration procedure of seawater samples at the field for simultaneous determination of radionuclides activities of ${ }^{90} \mathrm{Sr},{ }^{137} \mathrm{Cs},{ }^{226} \mathrm{Ra},{ }^{239,}{ }^{240} \mathrm{Pu}, \mathrm{U}$ and Th", Journal of Analytical Chemistry, Physics and Biology, T6, 2001.

25) N. H. Quang, D. D. Nhan, P. V. Toan, V. T. Nga, "Use tracer technique to investigate the dependence of soil-toplant transfer factor of $\mathrm{Sr}$ and Cs on the type of soils", International Conference on Isotopic and Nuclear Analytical Techniques for Health and Environment, IAEA, 10-13 June 2003, Vienna, Austria.

26) Le Ba Thuan, Nguyen Ba TIEN and Nguyen Hao Quang, "Evaluation of radiation protection for thermal power plant Nong Son, Quang Nam" Report to DOST Quang Nam, 2004.

27) Vuong Thu Bac, Pham Duy HiEn and Nguyen Hao QUANG, "forward trajectories of atmosphere air from Phuoc Dinh, Binh Thuan", Proceedings of the $6^{\text {th }}$ National Conference on Nuclear Physics and Techniques, Dalat, October 2005.

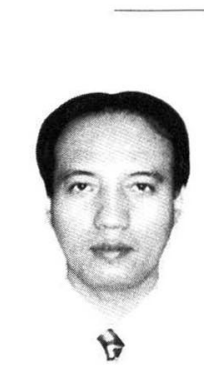

\section{Toan Ngoc Tran}

Present Position: Senior Researcher, Institute of Nuclear Science \& Technology, Vietnam Atomic Energy Commission (VAEC).

Studying at KosaKo Laboratory, Department of Nuclear Engineering \& Management, The University of Tokyo under JSPS Program.

Specialty: Radiation Dosimetry, Radiation

Protection.

E-mail: tntoanvn@gmail.com 